\title{
$\infty$
}

\section{Control of De-Lamination Phenomena in LTCC Zero- Shrinkage by Glass Infiltration Method}

\author{
Tae-Jin Jo and Dong-Hun $\mathrm{Yeo}^{+}$ \\ Bio-IT Convergence Center, Korea Institute of Ceramic Engineering and Technology, Seoul 153-801, Korea
}

Received October 10, 2011; Revised November 29, 2011; Accepted December 7, 2011

\begin{abstract}
A zero-shrinkage sintering process in which the shrinkage of $x-y$ axis is controlled to be zero is in great demand due to the trend of high integration in the ceramic modules. Among the zero-shrinkage sintering processes that are available, the proposed glass infiltration method where the viscous but fluidic glass infiltrates of the $\mathrm{Al}_{2} \mathrm{O}_{3}$ particles in the structure of $\mathrm{Al}_{2} \mathrm{O}_{3}$ /glass $/ \mathrm{Al}_{2} \mathrm{O}_{3}$ during firing is one of the applicable methods. However, the above proposed glass infiltration method has the problem of the warpage-like delamination. This occurred at the outermost surface of the multiple-bundle substrate. It is thought that the decomposed gas rapidly expands in low viscous glass to create vacant space. To solve this problem, the vacant space was tamped with $\mathrm{Al}_{2} \mathrm{O}_{3}$ particles to lead to the actual improvement of the sintered properties. With $15 \mathrm{wt} \%$ of tamping $\mathrm{Al}_{2} \mathrm{O}_{3}$ particles in glass, most of the vacant space disappeared. Fully densified zero-shrinkage substrate without delamination can be obtained.
\end{abstract}

Keywords: Glass infiltration, $\mathrm{Al}_{2} \mathrm{O}_{3} /$ Glass $/ \mathrm{Al}_{2} \mathrm{O}_{3}$ structure, Zero shrinkage, LTCC

\section{INTRODUCTION}

In recent years, the demands for miniaturization, high-speed, and multi-functionality of both the systems and the components of the communication devices are led by the rapid development of information technology with wireless communication [1,2]. As today's trend of miniaturization and weight-reduction is embedding certain specific functions found in the electronic circuit into a single module. Low temperature co-fired ceramic (LTCC) technology is focused as one of the applicable methods. The need for zero-shrinkage sintering process is one of the most important issues in LTCC in order to reduce the dimensional uncertainty of ceramic substrate during the firing process and to improve the precise matching between the ceramic layers $[3,4]$.

We have suggested the glass infiltration method in the previous study [5] including the structure of $\mathrm{Al}_{2} \mathrm{O}_{3} /$ glass $/ \mathrm{Al}_{2} \mathrm{O}_{3}$. During firing, the viscous but fluidic glass is thought to infiltrate into

${ }^{\dagger}$ Author to whom all correspondence should be addressed: E-mail: ydh7@kicet.re.kr

Copyright $\odot 2012$ KIEEME. All rights reserved.

This is an open-access article distributed under the terms of the Creative Commons Attribution Non-Commercial
License (http://creativecommons.org/licenses/by-nc/3.0) which permits unrestricted noncommercial use, License (http://creativecommons.org/licenses/by-nc/s to which permits unrestricted
distribution, and reproduction in any medium, provided the original work is properly cited.
$\mathrm{Al}_{2} \mathrm{O}_{3}$ particles in both the upper $\mathrm{Al}_{2} \mathrm{O}_{3}$ sheet and the lower one. But there was a problem in this method. Delamination occurred on the $\mathrm{Al}_{2} \mathrm{O}_{3}$ /glass interface. To solve this problem, we have suggested the use of $\mathrm{Pb}-\mathrm{B}-\mathrm{Si}-\mathrm{O}$ glass without $\mathrm{TiO}_{2}$ modified from the original $\mathrm{Pb}-\mathrm{B}$-Ti-Si-O glass. The lamination into a bundle of $\mathrm{Al}_{2} \mathrm{O}_{3} /$ glass $/ \mathrm{Al}_{2} \mathrm{O}_{3}$ structure produced a very dense zero-shrinkage LTCC in the previous study [6]. However, we had to solve an additional problem of warpage-like delamination which occurred at the outermost surface of multiple-bundle substrate.

In this study, delamination phenomenon in the multiple-bundle substrate with glass infiltration method for zero-shrinkage LTCC was investigated. The reason was analyzed to prohibit this phenomenon.

\section{EXPERIMENTS}

In this study, the commercial raw powders such as $\mathrm{Al}_{2} \mathrm{O}_{3}$ (particle size of $0.5 \mu \mathrm{m}$, AES-11, Sumitomo, Japan) and Pb-B-Ti-Si-O glass (particle size of $2.53 \mu \mathrm{m}$, density of $4.87 \mathrm{~g} / \mathrm{cm}^{3}, T_{g}$ of $455^{\circ} \mathrm{C}$ (sud1130, Phoenix PDE, KOREA) were chosen as starting materials. In addition, we fabricated a $\mathrm{Pb}-\mathrm{B}-\mathrm{Si}-\mathrm{O}$ glass without $\mathrm{TiO}_{2}$ by modifying the original $\mathrm{Pb}-\mathrm{B}-\mathrm{Ti}-\mathrm{Si}-\mathrm{O}$ glass composition as chosen above. 

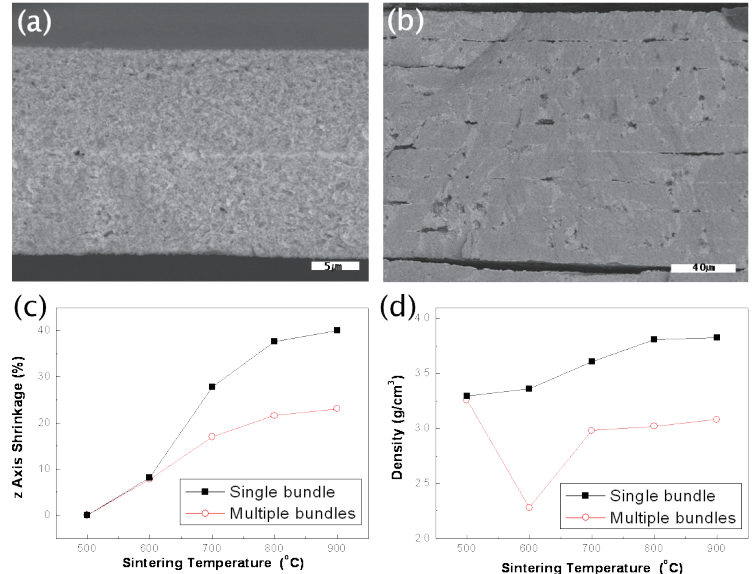

Fig. 1. SEM images and infiltration behavior of $\mathrm{Al}_{2} \mathrm{O}_{3} /$ glass $/ \mathrm{Al}_{2} \mathrm{O}_{3}$ substrates sintered at $900{ }^{\circ} \mathrm{C}$; (a) for a single bundle, (b) for multiple bundles in a substrate, (c) z-axial shrinkage of the substrate, and (d) sintered density.

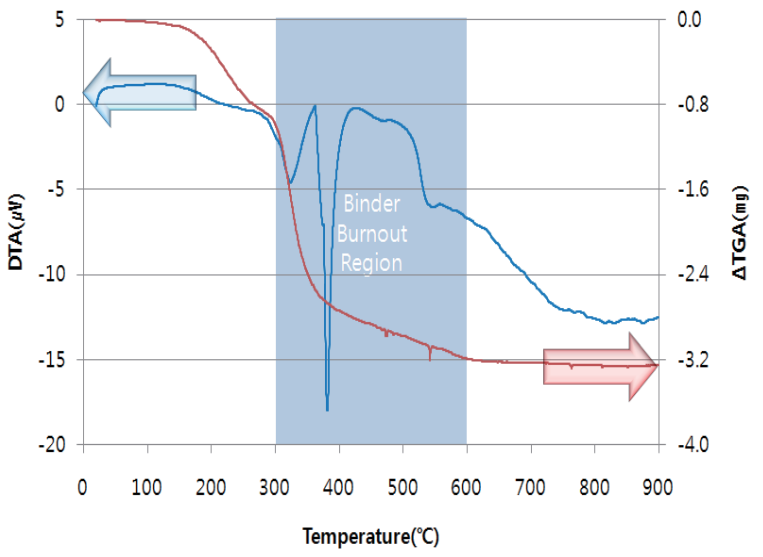

Fig. 2. TG/DTA analysis of a stacked substrate with 10 bundles of ' $\mathrm{Al}_{2} \mathrm{O}_{3}$ /glass $/ \mathrm{Al}_{2} \mathrm{O}_{3}$ '.

The each slurry of the glass and $\mathrm{Al}_{2} \mathrm{O}_{3}$ with viscosity of $800 \sim 1,000 \mathrm{cPs}$ was made by mixing toluene and ethanol with glass and $\mathrm{Al}_{2} \mathrm{O}_{3}$ powders for 24 hours. Then, every mixture was again mixed with PVB binder and plasticizer. Subsequently, the slurry was cast into green sheets with a thicknesses of about 10 50 $\mu \mathrm{m}$ through a comma coater.

Prepared green sheets of both $\mathrm{Al}_{2} \mathrm{O}_{3}$ and glass were pre-laminated into a sandwich structure of $\mathrm{Al}_{2} \mathrm{O}_{3} /$ glass $/ \mathrm{Al}_{2} \mathrm{O}_{3}$ at $1,000 \mathrm{psi}$ $60^{\circ} \mathrm{C}$ for 5 minutes. Pre-laminated green sheets were pressed warmly and iso-statically at $250 \mathrm{bar}, 80^{\circ} \mathrm{C}$ for 30 minutes. After WIP (warm iso-static pressing), stacked green sheets were cut into size of $15 \mathrm{~mm} \times 15 \mathrm{~mm}$. Organics in the prepared samples were burned out at $450^{\circ} \mathrm{C}$ for 1 hour with a heating rate of $2^{\circ} \mathrm{C} /$ min. Following the binder-burnout process, samples were sintered at $900^{\circ} \mathrm{C}$ for 20 minutes with a heating rate of $1^{\circ} \mathrm{C} / \mathrm{min}$. Then, they were slowly cooled in the furnace.

Density of sintered specimen was measured by Archimedean method. Its shrinkage was evaluated after the observation of a size difference between green and sintered one with an optical microscope (Icamscope-G, Icamscope, Korea). For microstructure observation, polished samples were observed by field emission scanning electron microscope (FE-SEM; JSM-6700F, Jeol, Tokyo, Japan). Dielectric constant and loss was measured with an impedance analyzer (E4991A, Agilent, U.S.A.) at $1 \mathrm{GHz}$.
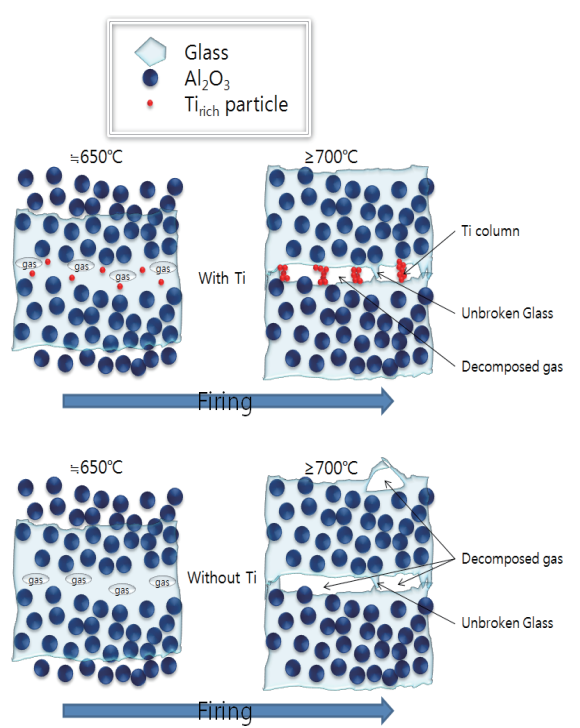

Fig. 3. Schematic diagram of warpage occurrence by the decomposed gas.

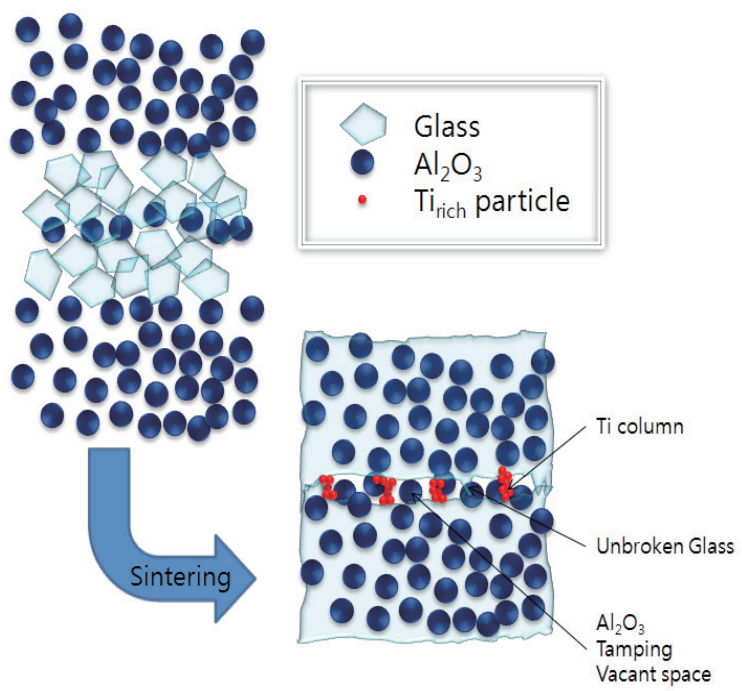

Fig. 4. Schematic diagram of the tamping vacant space with $\mathrm{Al}_{2} \mathrm{O}_{3}$ particles.

\section{RESULTS AND DISCUSSION}

Ti-free glass was prepared into a green sheet and then, laminated with a $\mathrm{Al}_{2} \mathrm{O}_{3}$ sheet. In Fig. 1(a), the microstructure of a single bundle (the word 'bundle' indicates a set of $\mathrm{Al}_{2} \mathrm{O}_{3} /$ glass/ $\mathrm{Al}_{2} \mathrm{O}_{3}$ with every single sheet) is shown. Full infiltration without any remarkable problem can be seen in [6], but in (b) of multiple bundles, delamination and warpage bulged in the image. Warpage-like delamination occurred at the glass region between layers. Serious warpage appeared at the outermost surface of the substrate. Just macroscopic shrinkage and density could be measured. They are shown in (c) and (d). Compared to a single bundle, the $\mathrm{z}$-axial shrinkage and the density values of multiple bundles are much lower than those of the single bundles. Especially, density decreased stiffly from $500^{\circ} \mathrm{C}$ to $600^{\circ} \mathrm{C}$, then again increased stiffly to $700^{\circ} \mathrm{C}$ but it was saturated above that temperature. Despite the variation in glass amount, there was no remarkable change in the warpage state. Any other variation in process factors, such as the kind of binder, sintering schedule 

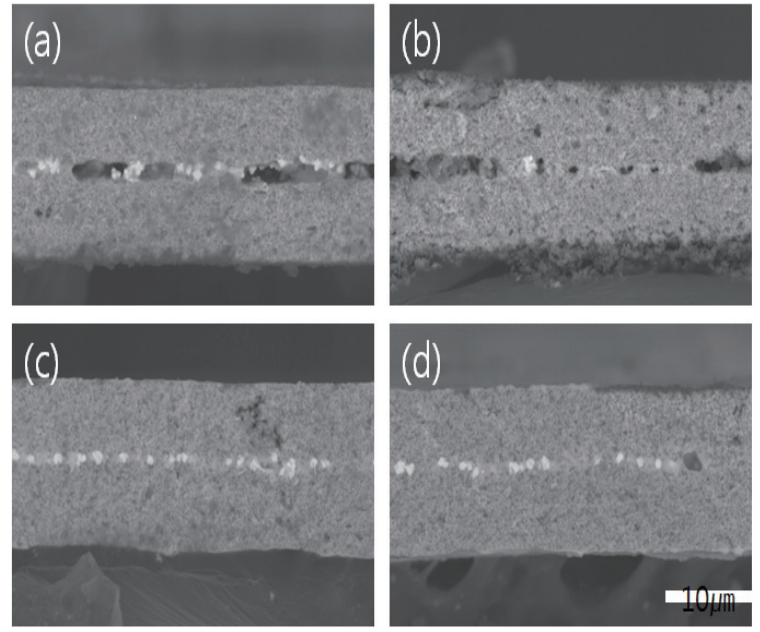

Fig. 5. Effect of tamping vacant space with $\mathrm{Al}_{2} \mathrm{O}_{3}$ particles; (a) $5 \mathrm{wt} \%$, (b) $10 \mathrm{wt} \%$, (c) $15 \mathrm{wt} \%$, and (d) $20 \mathrm{wt} \%$ of $\mathrm{Al}_{2} \mathrm{O}_{3}$ with glass.
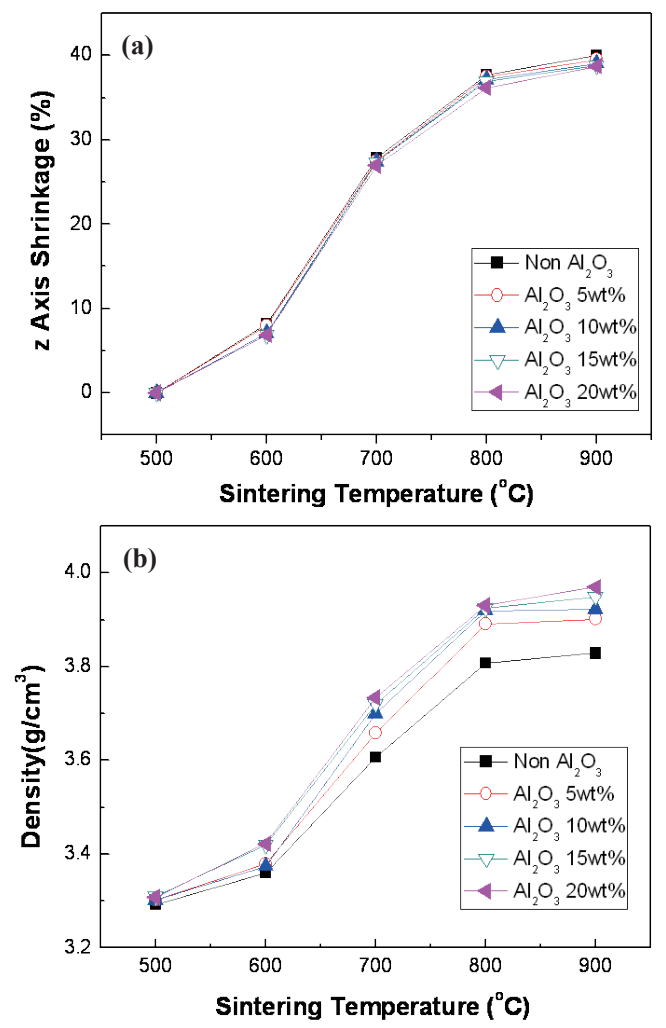

Fig. 6. Comparison of the $\mathrm{z}$-axial shrinkage and density with variation of the tamping amount; (a) z-axial shrinkage with variation of the tamping amount, and (b) density with the tamping amount.

and so on, did not affect the warpage state.

It is thought that too low $T_{g}$ of used Pb-glass, both with Ti and without Ti, does not guarantee the sufficient burnout of the binder. Remnant carbon in the glass region decomposes as the temperature increases. The gas expansion by decomposition of remnant the carbon creates a vacant space in the less viscous glass region. TG/DTA curve of the stacked substrate is shown in Fig. 2. It can be confirmed that the binder burnout range is from $300^{\circ} \mathrm{C}$ to $600^{\circ} \mathrm{C}$. And, the gas gradually diffuses out of the body but the vacant space remains. But, in the case of Pb-glass with $\mathrm{Ti}$, Ti-column is thought to sustain gas expansion. So, the
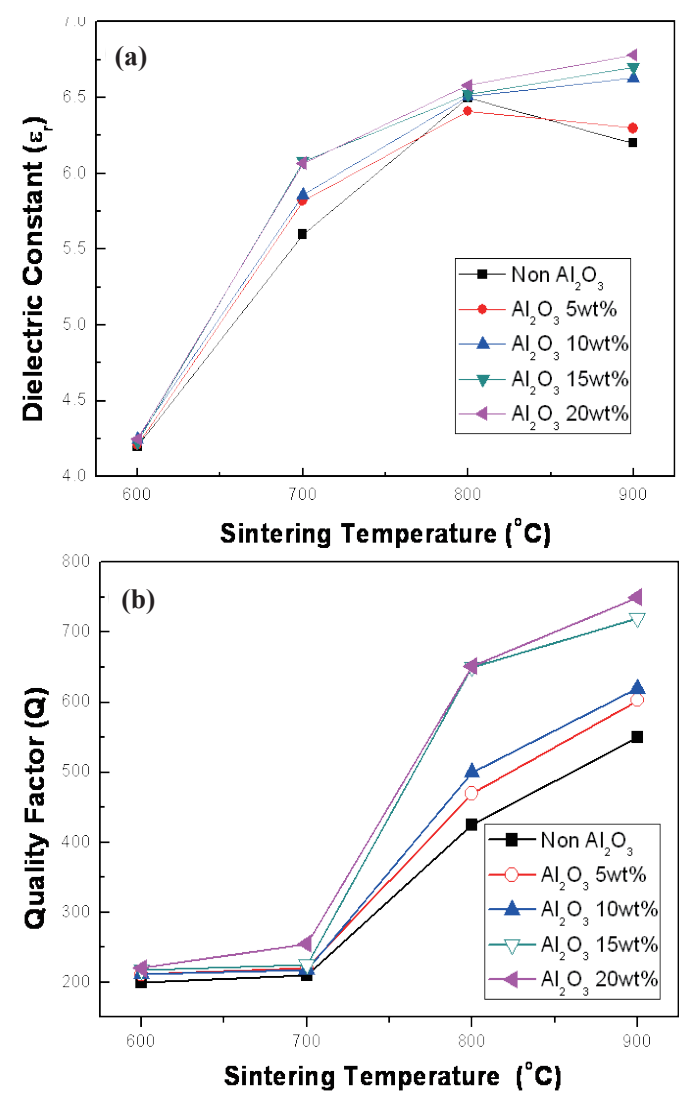

Fig. 7. Dielectric properties of the tamped substrate.

warpage at the outermost surface does not occur, while without $\mathrm{Ti}$, gas expansion makes serious warpage. Gas decomposition above $T_{g}$ could be confirmed by the density drop from $500^{\circ} \mathrm{C}$ to $600^{\circ} \mathrm{C}$ shown in Fig. 1(d). As decomposed gas expands rapidly, density decrease stiffly, then as the gas diffuses out, density may increase. This hypothesis is shown in Fig. 3.

The warpages at the surface made the measurement of the dielectric properties difficult, as the measurement requires a exact contact between the probe and the specimen. And any other variation in the process factor could not improve the state. Then, the tamping of the vacant space in case of glass with $\mathrm{Ti}$ was suggested, as shown in Fig. 4. After sintering, decomposed gas diffuses out to make a vacant space in the body [7], so tamping that space with other particles would be a good trial. And so, Pb-glass powder with $\mathrm{Ti}$ composition was mixed with $\mathrm{Al}_{2} \mathrm{O}_{3}$ powders from 0 to $20 \mathrm{wt} \%$.

The microstructures of the sintered samples obtained by the tamping of $\mathrm{Al}_{2} \mathrm{O}_{3}$ particles are shown in Fig. 5. $\mathrm{As}_{2} \mathrm{Al}_{2} \mathrm{O}_{3}$ amount increases, vacant spaces gradually tamped and they were fully done at $15 \mathrm{wt} \%$. Ti-columns also exist, but the packing state of $\mathrm{Al}_{2} \mathrm{O}_{3}$ with glass appeared much better than before.

It is suggested that a certain amount of crystalline phase in the glass matrix restrains pore occurrence as well as its movement [8]. Without the crystalline phase, small pores can easily move to coalescence together and a resultant large pore has larger volume than the summation of the small pores because of low viscosity. But with the crystalline phase to some extent, pore movement is hindered by the crystalline particles themselves and also by the high viscosity caused due to their existence.

Z-axial shrinkages and measured densities are compared in Fig. 6. In (a) and (b), as tamping amount increases, shrinkage showed no remarkable difference among the values at the same temperature, while there exist remarkable ones in the density 
plot, despite the addition of low-density material of $\mathrm{Al}_{2} \mathrm{O}_{3}$. It is considered that the replacement of the $\mathrm{Al}_{2} \mathrm{O}_{3}$ particles with vacant space increases in density. The resultant shrinkage in $x-y$ plane was below $0.1 \%$, and that along the $\mathrm{z}$ direction was about $40 \%$.

Dielectric properties of a tamped substrate are shown in Fig. 7. As the tamping amount increases, both the dielectric constant and the quality factor increased. It is thought believed that the tamped $\mathrm{Al}_{2} \mathrm{O}_{3}$ particles with the dielectric constant about 10 , instead of the vacant space, made an increase in the dielectric constant. And also, reduced vacant space showed higher quality factor.

\section{CONCLUSIONS}

In this study, delamination phenomenon in multiple bundles of glass infiltration method for zero-shrinkage LTCC substrate was investigated and the reason was analyzed to prohibit this phenomenon. Warpage-like delamination occurred at the glass region between layers and serious warpage appeared at the outermost surface of the substrate. This space in the glass region between the layers arises due to the gas expansion. This is derived from the decomposition of the remnant carbon during firing (300-600 ${ }^{\circ}$ ) without a sufficient binder burnout because of low $T_{g}$ of used glass. It is thought that the decomposed gas expands rapidly in low viscous glass to create a vacant space. Tamping vacant space, which is sustained by the Ti-columns is thought to improve the sintered properties of zero shrinkage substrate.
From this assumption, tamping vacant space with $\mathrm{Al}_{2} \mathrm{O}_{3}$ particles is thought to lead the actual improvement of the sintered properties. With $15 \mathrm{wt} \%$ of tamping $\mathrm{Al}_{2} \mathrm{O}_{3}$ particles in glass, most of the vacant space disappeared and fully densified zero-shrinkage substrate without delamination could be obtained.

\section{REREFENCES}

[1] B. Schwartz, "Microelectronics Packaging : II ", Am. Ceram. Soc. Bull., 56, 433 (1977)

[2] Y. Imanaka, "Multilayered Low Temperature Cofired Ceramics (LTCC) Technology", Springer, New York, pp. 1-5 (2005)

[3] K. R. Mikeska and R. C. Mason, 6th International SAMPE Electronics Conference, pp. 22-25 (1992)

[4] S. D. Park and H. K. Kang, J. Microelectronics \& Packaging Soc., 6, 25 (1999)

[5] J. H. You, D. H. Yeo, H. S. Shin, J. H. Kim and H. G. Yoon, J. Electroceramics, 23, pp. 367-371 (2009) [DOI: 10.1007/s10832-0089469-3].

[6] T. J. Jo, D. H. Yeo, H. S. Shin, Y. W. Hong and Y. S. Cho, Trans. Electr. Electron. Mater., 12, pp.32-34 (2011) [DOI: 10.4313/ TEEM.2011.12.1.32].

[7] James S. Reed : translated by S. S. Kim, C. H. Kim and J. Y. Park, Principles of Ceramic Processing, Pan Korea Book Corporation, pp. 514-516 (1996).

[8] B. S. Kim, E. S. Lim, J. H. Lee and J. J. Kim, J. Eur. Ceram. Soc., 27, pp.819-824 (2007) [DOI: 10.1016/j.jeurceramsoc.2006.04.013]. 